Robinson, D. S. (1989) The antidepressant effects of buspirone and its analogue, gepirone. Family Practice Recertification, 11 (suppl. 9), 24-31.

LUIS M. IRUELA

VINCENTE IBAÑEZ-ROJO

Luis CABALlero

ENRIQUE BACA

Department of Psychiatry

Universidad Autonoma de Madrid

Clinica Puerta de Hierro

San Martin de Porres, 4

28035 Madrid, Spain

\section{Clinical irrelevance of HAD factor structure}

SIR: Moorey et al (Journal, February 1991, 158, 255-259) happily reported the two distinct, stable, consistent and reliable factors on factor analysis of the Hospital Anxiety and Depression Scale (HAD) which corresponded to the questionnaire's anxiety and depression subscales. Clinical experience of using the HAD, does not however, support this bidimensional solution. In our trial with HAD in patients suffering from clinical anxiety and depression we found that the mean anxiety subscale scores were much higher in the depressed patients higher than the anxiety score of the anxiety disorder patients and also higher than the depression subscale score of the depressive disorder patients! Thus the two subscales hardly discriminate between clinical anxiety and depression, irrespective of the statistical derivations. In fact, the authors themselves noted substantially more anxiety than depression but they have not reported the anxiety and depression subscale scores separately in their depressed and anxiety patients. It seems that the total HAD scores are more meaningful clinically than the subscale scores. At the moment HAD is a widely used instrument and it would be very useful if prospective authors gave subscale scores and correlated these with the clinical observations.

\section{S. K. Chaturved}

Department of Psychiatry

National Institute of Mental Health \& Neurosciences Bangalore, India

\section{A possible antiaggressive efiect of cyproterone acetate}

SIR: Some clinical studies suggest that testosterone may influence certain kinds of aggressive behaviour in human males (e.g. Olweus et al, 1980).

We would like to report the case of a young psychotic patient whose aggressive and impulsive behaviour has been dramatically improved by a competitive inhibitor of the androgen binding site - cyproterone acetate (CPA) - whereas a LHRH analogue treatment (reducing the plasma testosterone level to castration values) failed to maintain the antiaggressive effect of CPA.

Case report. A 30-year-old man with a psychiatric diagnosis of infantile psychosis was studied. Since the age of ten, he had shown aggressive and impulsive behaviour treated with varying combinations of neuroleptic drugs, propanolol, benzodiazepines or carbamazepine, depending on the patient's level of aggression.

During the month which preceded this study, his aggressive behaviour gradually increased, resulting in verbal and physical aggression against either objects or staff members, leading to occasional injuries. The patient's last treatment which included levomepromazine $(300 \mathrm{mg} / \mathrm{d})$, carbamazepine $(600 \mathrm{mg} / \mathrm{d})$ and diazepam $(200 \mathrm{mg} / \mathrm{d})$, was absolutely ineffective. Instances of physical aggression occurred almost every day and sometimes twice a day, and required immediate sedative injection and isolation. At the time of this observation, the level of aggression assessed on the OAS Scale (Yodofsky et al, 1986) reached 18.

Before starting the CPA treatment, the plasma testosterone level was within the normal range $(5.2 \mathrm{ng} / \mathrm{ml})$ as were the other plasma hormone levels (LH, prolactin, FSH, $\Delta 4$ androstene-dione).

In a first step, the CPA treatment was added to the former treatment at a daily dosage of $50 \mathrm{mg}$ and slowly increased up to $200 \mathrm{mg}$ daily. His aggressive behaviour gradually decreased over a period of one month, making it possible to reduce the neuroleptic treatment down to $150 \mathrm{mg}$ /day and to withdraw the carbamazepine and diazepine prescriptions. The level of aggression became 0 on the OAS. No significant change was observed in the plasma testosterone level.

This improvement was maintained for a period of four months. Then we decided to test if a reduction in the testosterone gonadal secretion (without affecting the androgen receptor level) would produce the same clinical effect. A monthly injection of a long-lasting LHRH analogue treatment was started and the CPA treatment was withdrawn after the second injection (gosereline acetate $3.6 \mathrm{mg}$ monthly).

Whereas the testosterone level dropped to castration values (the $0.25 \mathrm{ng} / \mathrm{ml}$ remaining originated from the adrenal), the aggression score returned to its initial value fifteen days after the interruption of CPA treatment. CPA had to be reintroduced in order to control the patient's aggression.

The beneficial effect of CPA treatment on aggressive behaviour could be explained either by its well known antiandrogenic effects or by its progestational properties leading to antioestrogenic effects. LHRH analogue treatment is devoid of progestational effects. With regard to the lack of clinical efficacy of LHRH analogue treatment, the antioestrogenic hypothesis seems more plausible.

Some preclinical studies suggest that, in fact, oestrogens could be more involved than androgens in 
aggressive behaviour. The level of aggression generated by non-aromatisable androgens is generally lower than those produced by testosterone (aromatised into oestradiol in the brain) or oestrogens themselves (Brain, 1977).

Additional studies on violent subjects are required to confirm the antiaggressive effect of CPA on nonsexual violent behaviour and to clarify this effect and the mechanisms involved.

BraIN, P. (1977) Pituitary gonadal influences on social aggression In Hormones and Aggressive Behavior (ed. B. B. Svare), pp. 3-25. New York: Plenum Press.
Olweus, D., Mattson, A., Schalling, D., el al (1980) Testosterone, aggression, physical and personality dimensions in normal adolescent males. Psychosomatic Medicine, 42, 253-296.

YudOFSKY, S. C., Silver, J. M., JACKson, W., et al (1986) The overt aggression scale for the objective rating of verbal and physical aggression. American Journal of Psychiatry, 143, 35-39.

FLORENCE THIBAUT JeAn Marc KuHN

Department of Psychiatry

LUCIEN COLONNA

CHS Rouvray

76301 Sotteville les Rouen, France

\section{CORRIGENDUM}

Journal, May 1991, 158, (Suppl. 10), 85-86. The sentence beginning at the bottom of page 85 should read "Two decades on, we are similarly failing to acknowledge the presence of female perversions, including maternal incest."

\section{A HUNDRED YEARS AGO}

\section{Discussion on Hypnotism in Dublin}

Dr F. R. Cruise, one of the consulting physicians to the Mater Misericordiae Hospital, Dublin, who opened a discussion on hypnotism at the Royal Academy of Medicine in Ireland a short time ago, very candidly confessed that a year ago he was quite undecided whether the usual statements of the chief French observers of hypnotism "were either astounding facts or most audacious falsehoods", and, indeed, that if he had heard his own present opinions a year ago he would have been very sceptical about them. However, a visit to Nancy and Paris, and a short study of the cliniques of Liebeault, Bernheim, Luys, Auguste Voisin and Charcot, have convinced him "that hypnotism is a reality, and a great means towards cure, one which can never be crushed by ignorant and baseless criticism"; and "I believe", he continues, "that it is our duty, and our imperative duty, to do it justice, and rescue it from the hands of charlatans". He had been much impressed in Paris by seeing M. Auguste Voisin hypnotise an insane dipsomaniac girl whom, "by repeated hypnotism and suggestion $M$. Voisin cured not only of her mania, but also of her evil propensity"; and since his return from France, Dr J. J. Murphy had been equally successful on a case of dipsomania under his care. Dr G. C. Kingsbury followed with a clear speech explaining the methods and uses of hypnotism as practised at Nancy, some of which he had corroborated in England, and pleading that a fair trial should be given to the treatment. Of the twelve others who joined in the discussion, there were several who related cases of pain or morbid habits in which hypnotism had been followed by relief and improvement, and only one who objected to its employment.

\section{Reference}

British Medical Journal, 13 June 1891, 1299.

\section{Researched by Henry Rollin, Emeritus Consultant Psychiatrist, Horton Hospital, Surrey.}

